\title{
Bivalirudin versus Heparin Monotherapy in Myocardial Infarction
}

\author{
D. Erlinge, E. Omerovic, O. Fröbert, R. Linder, M. Danielewicz, M. Hamid, \\ E. Swahn, L. Henareh, H. Wagner, P. Hårdhammar, I. Sjögren, J. Stewart, \\ P. Grimfjärd, J. Jensen, M. Aasa, L. Robertsson, P. Lindroos, J. Haupt, \\ H. Wikström, A. Ulvenstam, P. Bhiladvala, B. Lindvall, A. Lundin, T. Tödt, \\ D. loanes, T. Råmunddal, T. Kellerth, L. Zagozdzon, M. Götberg, J. Andersson, \\ O. Angerås, O. Östlund, B. Lagerqvist, C. Held, L. Wallentin, F. Scherstén, \\ P. Eriksson, S. Koul, and S. James
}

The authors' full names, academic degrees, and affiliations are listed in the Appendix. Address reprint requests to Dr. Erlinge at the Department of Cardiology, Clinical Sciences, Lund University, Skåne University Hospital, S-221 85 Lund, Sweden, or at david.erlinge@med.lu.se.

This article was published on August 27, 2017, at NEJM.org.

N Engl J Med 2017;377:1132-42. DOI: $10.1056 /$ NEJMoal706443

Copyright @ 2017 Massachusetts Medical Society.
ABSTRACT

BACKGROUND

The comparative efficacy of various anticoagulation strategies has not been clearly established in patients with acute myocardial infarction who are undergoing percutaneous coronary intervention (PCI) according to current practice, which includes the use of radial-artery access for PCI and administration of potent P2 $\mathrm{Y}_{12}$ inhibitors without the planned use of glycoprotein IIb/IIIa inhibitors.

\section{METHODS}

In this multicenter, randomized, registry-based, open-label clinical trial, we enrolled patients with either ST-segment elevation myocardial infarction (STEMI) or non-STEMI (NSTEMI) who were undergoing PCI and receiving treatment with a potent $\mathrm{P}_{12} \mathrm{Y}_{12}$ inhibitor (ticagrelor, prasugrel, or cangrelor) without the planned use of glycoprotein IIb/IIIa inhibitors. The patients were randomly assigned to receive bivalirudin or heparin during PCI, which was performed predominantly with the use of radial-artery access. The primary end point was a composite of death from any cause, myocardial infarction, or major bleeding during 180 days of follow-up.

RESULTS

A total of 6006 patients (3005 with STEMI and 3001 with NSTEMI) were enrolled in the trial. At 180 days, a primary end-point event had occurred in $12.3 \%$ of the patients (369 of 3004) in the bivalirudin group and in 12.8\% (383 of 3002) in the heparin group (hazard ratio, $0.96 ; 95 \%$ confidence interval $[\mathrm{CI}], 0.83$ to $1.10 ; \mathrm{P}=0.54$ ). The results were consistent between patients with STEMI and those with NSTEMI and across other major subgroups. Myocardial infarction occurred in $2.0 \%$ of the patients in the bivalirudin group and in $2.4 \%$ in the heparin group (hazard ratio, $0.84 ; 95 \% \mathrm{CI}, 0.60$ to $1.19 ; \mathrm{P}=0.33$ ), major bleeding in $8.6 \%$ and $8.6 \%$, respectively (hazard ratio, 1.00 ; $95 \% \mathrm{CI}, 0.84$ to $1.19 ; \mathrm{P}=0.98$ ), definite stent thrombosis in $0.4 \%$ and $0.7 \%$, respectively (hazard ratio, $0.54 ; 95 \% \mathrm{CI}, 0.27$ to $1.10 ; \mathrm{P}=0.09$ ), and death in $2.9 \%$ and $2.8 \%$, respectively (hazard ratio, 1.05; 95\% $\mathrm{CI}, 0.78$ to $1.41 ; \mathrm{P}=0.76$ ).

CONCLUSIONS

Among patients undergoing PCI for myocardial infarction, the rate of the composite of death from any cause, myocardial infarction, or major bleeding was not lower among those who received bivalirudin than among those who received heparin monotherapy. (Funded by the Swedish Heart-Lung Foundation and others; VALIDATE-SWEDEHEART ClinicalTrialsRegister.eu number, 2012-005260-10; ClinicalTrials.gov number, NCT02311231.) 
NTICOAGULATION WITH HEPARIN OR bivalirudin, in combination with antiplatelet agents such as aspirin, $\mathrm{P}_{12}$ inhibitors, and glycoprotein IIb/IIIa inhibitors, is routinely used to improve angiographic and clinical outcomes in patients undergoing percutaneous coronary intervention (PCI) for acute coronary syndromes. ${ }^{1-6}$ The use of more potent $\mathrm{P} \mathrm{Y}_{12}$ inhibitors (prasugrel, ticagrelor, and cangrelor) has further improved clinical outcomes over those seen with the use of clopidogrel, which was the previous standard treatment option for such patients. ${ }^{7,8}$ The goal of anticoagulant management is to balance the risk of thrombotic complications, such as reinfarction and stent thrombosis, with the risk of bleeding complications. Several trials have shown that the risk of bleeding associated with bivalirudin therapy is lower than that associated with heparin therapy. ${ }^{1,6,9-11}$ However, these trials were conducted before PCI was performed with the use of routine radial-artery access and before the introduction of potent $\mathrm{P}_{2} \mathrm{Y}_{12}$ inhibitors, or they did not assess the use of heparin monotherapy (without glycoprotein IIb/IIIa inhibitors) as an alternative to bivalirudin during PCI in patients with acute coronary syndromes.

Three previous trials that compared bivalirudin with heparin monotherapy in patients with acute coronary syndromes yielded conflicting results. These trials had different approaches regarding the use of heparin before randomization, bivalirudin after PCI, and potent $\mathrm{P}_{12} \mathrm{Y}_{12}$ inhibitors..$^{5,12,13}$ The aim of the current trial was to investigate whether the use of bivalirudin would result in a lower rate of the composite of death from any cause, myocardial infarction, and major bleeding events than heparin monotherapy (without planned use of glycoprotein IIb/IIIa inhibitors) among patients with either ST-segment elevation myocardial infarction (STEMI) or nonSTEMI (NSTEMI) who were undergoing PCI predominantly with the use of radial-artery access and who were receiving treatment with potent $\mathrm{P}_{12}$ inhibitors.

METHODS

\section{TRIAL DESIGN}

VALIDATE-SWEDEHEART (Bivalirudin versus Heparin in ST-Segment and Non-ST-Segment Elevation Myocardial Infarction in Patients on Modern Antiplatelet Therapy in the Swedish Web
System for Enhancement and Development of Evidence-based Care in Heart Disease Evaluated according to Recommended Therapies Registry Trial) is a registry-based, multicenter, randomized, controlled, open-label clinical trial. Trial coordination, database management, and statistical analyses were performed at Uppsala Clinical Research Center. The trial was approved nationally by the ethics committee at Lund University and by the Swedish Medical Products Agency. An executive committee, with assistance from all the investigators, was responsible for the design, conduct, and reporting of the trial. The agencies that funded the trial had no access to the trial data and no role in the design, conduct, or reporting of the trial. The authors vouch for the accuracy and completeness of the data and analyses and for the fidelity of the trial to the protocol, which is available with the full text of this article at NEJM.org.

\section{DATA SOURCES}

This trial used the platform of preexisting health care registries for enrollment, randomization, collection of data, and follow-up (for further details, see the Supplementary Appendix, available at NEJM.org). All patients at participating centers who were entered into the SWEDEHEART registry were evaluated for potential enrollment in the trial. Baseline patient demographic data were obtained from the SWEDEHEART registry, as were data on angiographic and PCI variables, in-hospital complications, and medications at baseline and at discharge, as well as International Classification of Diseases, 10th Revision hospital discharge codes. Information on death was obtained from the Swedish national population registry for all patients until the end of the trial (see the Supplementary Appendix). Answers to trial-specific questions were collected in a separate trialspecific module embedded in the SWEDEHEART online questionnaire.

\section{PATIENTS}

Patients who were admitted to the hospital with a diagnosis of STEMI or NSTEMI and for whom urgent PCI was planned were eligible for participation in the trial if they met all other inclusion criteria and did not meet any exclusion criteria (for a complete list of inclusion and exclusion criteria, see the Supplementary Appendix). ${ }^{14}$ Treatment with ticagrelor, prasugrel, or cangrelor before PCI was required as a condition of enroll- 
ment. Patients were excluded if they had received a glycoprotein IIb/IIIa inhibitor or if use of such an agent was planned. However, emergency, unplanned use of a glycoprotein IIb/IIIa inhibitor was allowed and recorded.

In patients with STEMI, intravenous administration of up to $5000 \mathrm{U}$ of unfractionated heparin was permitted before arrival at the catheterization laboratory. In all patients (i.e., those with STEMI or NSTEMI), if heparin had not been administered previously, intraarterial administration of up to $3000 \mathrm{U}$ of heparin was allowed in the catheterization laboratory before angiography, in accordance with local practices. Patients who received more than $5000 \mathrm{U}$ of intravenous heparin before they arrived at the catheterization laboratory or more than $3000 \mathrm{U}$ of intraarterial heparin in the catheterization laboratory before they underwent angiography were excluded from the trial. All patients received pretreatment with aspirin, in accordance with local practices (usually at a dose of $300 \mathrm{mg}$ orally).

\section{TRIAL PROCEDURES}

In patients with STEMI, witnessed oral consent was obtained after angiography and before randomization. Within the following 24 hours, after written information about the trial had been provided, the patients confirmed further participation by providing written informed consent. In patients with NSTEMI, written consent was obtained before angiography.

After angiography but before PCI, the patients were randomly assigned, through the online Swedish Coronary Angiography and Angioplasty Registry (SCAAR; which is a component of the SWEDEHEART registry), to receive in an open-label fashion either intravenous bivalirudin (the Medicines Company) or intraarterial unfractionated heparin (LEO Pharma). Randomization was performed in a 1:1 ratio in permuted blocks, with the use of a computer-generated list, with stratification according to type of myocardial infarction (STEMI or NSTEMI) and hospital.

Bivalirudin was administered as an intravenous bolus of $0.75 \mathrm{mg}$ per kilogram of body weight followed by an infusion of $1.75 \mathrm{mg}$ per kilogram per hour. Treatment was started as soon as PCI of the culprit lesion was planned. Continuation of the bivalirudin infusion after PCI until completion of the last vial was strongly recommended. For the patients assigned to receive heparin, a total dose of 70 to $100 \mathrm{U}$ per kilogram was recommended.

Measurement of the activated clotting time 10 minutes after the initiation of treatment with heparin or bivalirudin was strongly recommended. Administration of an additional bolus of the assigned drug (bivalirudin at a dose of $0.3 \mathrm{mg}$ per kilogram or heparin at dose determined by the physician) was recommended if the activated clotting time was shorter than $250 \mathrm{sec}$. Treatment with a P2Y ${ }_{12}$ inhibitor and aspirin (75 to $160 \mathrm{mg}$ daily) was recommended for 1 year after PCI. ${ }^{15}$

\section{END POINTS}

The primary end point was the composite of death from any cause, myocardial infarction, or major bleeding events at 180 days. Secondary end points included separate analyses of the primary end point in the STEMI and NSTEMI strata, the individual components of the primary end point, stroke, and stent thrombosis. A complete list of trial end points and prespecified definitions are provided in the Supplementary Appendix. Deaths were classified as cardiovascular or noncardiovascular, and myocardial infarction was defined according to the third universal definition. We categorized major bleeding as type 2, 3, or 5 according to the Bleeding Academic Research Consortium (BARC) scale (with type 2 indicating any overt, actionable sign of bleeding; type 3 bleeding with a decrease in the hemoglobin of $>3 \mathrm{~g}$ per deciliter, any transfusion, cardiac tamponade, or intracranial or ocular involvement; and type 5 fatal bleeding).

Research nurses screened for clinical end-point events by contacting the patients or first-degree relatives by telephone 7 days and 180 days after PCI. If a patient was suspected to have had a clinical end-point event (i.e., death, myocardial infarction, bleeding, or stroke), the patient's health care records were subjected to central blinded adjudication to determine the cause of the event according to prespecified criteria. If the patient or relatives could not be contacted after the nurses had placed repeated telephone calls and mailed a letter, information was collected through review of hospital records.

\section{STATISTICAL ANALYSIS}

We hypothesized that at 180 days, the rate of the composite of death from any cause, myocardial 
infarction, or major bleeding events would be lower among patients who had received bivalirudin than among those who had received heparin. We anticipated a rate of primary end-point events of $15.8 \%$ at 180 days in the heparin group among patients with either STEMI or NSTEMI. We estimated that a sample size of 3000 patients each in the STEMI and NSTEMI strata (a number that accounts for deviations from treatment and attrition) would provide $80 \%$ power to detect a hazard ratio for an event with bivalirudin versus heparin of 0.75 in each stratum. We estimated that a sample size of 6000 for the entire trial would provide $97.5 \%$ power to detect a hazard ratio of 0.75 .

All analyses were performed on an intentionto-treat basis. Time-to-event end points are presented with the use of Kaplan-Meier plots, and treatment differences were assessed with the use of the log-rank test and Cox regression. Data on patients who were lost to follow-up were censored at the date of the last contact with the patient. The main subgroup analysis examined the primary end point and its components in the STEMI and NSTEMI strata. Additional subgroup analyses for the primary end point, which were prespecified in the statistical analysis plan, were performed with the use of a proportional-hazards model, with factors including treatment, subgroup, and interaction between treatment and subgroup. Medications at discharge were compared with the use of the chi-square test, without imputation of missing data. Two-tailed $\mathrm{P}$ values of less than 0.05 were considered to indicate statistical significance. All results are reported without adjustment for multiplicity.

\section{RESULTS}

\section{TRIAL POPULATION}

The trial was conducted at 25 of the 29 PCI centers in Sweden. Between June 2014 and September 2016, a total of 6006 patients (3005 with STEMI and 3001 with NSTEMI) underwent randomization; these patients represent $47.8 \%$ of the 12,561 patients in Sweden who presented to one of the participating centers during the enrollment period with an initial diagnosis of STEMI or NSTEMI and for whom PCI was planned (i.e., screened patients) and $70.0 \%$ of the 8585 patients who were potentially eligible for enrollment in the trial (Fig. S1 in the Supplementary Appendix). A total of 3004 patients were as- signed to the bivalirudin group, and 3002 to the heparin group.

Baseline demographic and clinical characteristics for all patients enrolled in the trial and for the patients who were screened but not enrolled in the trial are shown in Table 1 . The baseline characteristics were well balanced between treatment groups. Follow-up data for the primary end point were obtained for $98.9 \%$ of the patients by means of a telephone call, review of hospital records, or both. Follow-up data on deaths were obtained for all patients from the records of the Swedish National Population Registry. Additional data on patient characteristics and medications at baseline, as well as data on completeness of follow-up, are available in Tables S1 and S2 and Figure S1 and on page 12 in the Supplementary Appendix.

PCI was performed with the use of radialartery access in 5424 patients $(90.3 \%)$, with this approach used in a similar proportion of patients in the two treatment groups. The $\mathrm{P}_{12} \mathrm{Y}_{12}$ inhibitor used during the procedure was ticagrelor in 5697 patients (94.9\%), prasugrel in 125 (2.1\%), and cangrelor in 21 (0.3\%). The $\mathrm{P} \mathrm{Y}_{12}$ inhibitor was administered at least 1 hour before PCI in $61.6 \%$ of the patients, and heparin $(\leq 5000 \mathrm{U})$ was administered before arrival at the catheterization laboratory in $36.6 \%$. Additional information on periprocedural characteristics of the patients is available in Tables S3 and S4 in the Supplementary Appendix.

Crossover between the two treatment groups occurred in $0.5 \%$ of the patients. The mean maximum activated clotting time during PCI was $386 \mathrm{sec}$ in the bivalirudin group and $305 \mathrm{sec}$ in the heparin group. A total of $65.3 \%$ of the patients treated with bivalirudin received a prolonged infusion (mean duration, $57 \mathrm{~min}$ ). Rescue glycoprotein IIb/IIIa inhibitor therapy was administered in 71 patients $(2.4 \%)$ in the bivalirudin group and in $85(2.8 \%)$ in the heparin group. At discharge, ticagrelor was prescribed for 5149 patients $(85.7 \%)$, prasugrel for $57(0.9 \%)$, and

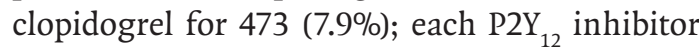
was prescribed for a similar proportion of patients in the two treatment groups (Table $\mathrm{S} 5$ in the Supplementary Appendix).

\section{CLINICAL OUTCOMES}

The rate of the primary end point did not differ significantly between the treatment groups at 30 


\begin{tabular}{|c|c|c|c|c|}
\hline Characteristic & $\begin{array}{l}\text { Bivalirudin } \\
\text { Group } \\
(\mathrm{N}=3004)\end{array}$ & $\begin{array}{l}\text { Heparin } \\
\text { Group } \\
(\mathrm{N}=3002)\end{array}$ & $\begin{array}{l}\text { All Patients } \\
\text { Enrolled in the Trial } \\
(\mathrm{N}=6006)\end{array}$ & $\begin{array}{l}\text { Screened Patients Not } \\
\text { Enrolled in the Trial } \\
(\mathrm{N}=6555)\end{array}$ \\
\hline STEMI — no. (\%) & $1501(50.0)$ & $1504(50.1)$ & $3005(50.0)$ & $2318(35.4)$ \\
\hline Male sex — no. (\%) & $2229(74.2)$ & $2177(72.5)$ & $4406(73.4)$ & $4555(69.5)$ \\
\hline \multicolumn{5}{|l|}{ Age } \\
\hline Median - yr & 68.0 & 68.0 & 68.0 & 71.0 \\
\hline Interquartile range $-\mathrm{yr}$ & $59.0-75.0$ & $60.0-75.0$ & $60.0-75.0$ & $62.0-79.0$ \\
\hline$\geq 65 \mathrm{yr}-$ no. (\%) & $1819(60.6)$ & $1852(61.7)$ & $3671(61.1)$ & $4528(69.1)$ \\
\hline \multicolumn{5}{|l|}{ Body-mass index $\uparrow$} \\
\hline Median & 26.8 & 26.9 & 26.9 & 26.9 \\
\hline Interquartile range & $24.5-29.7$ & $24.5-29.7$ & $24.5-29.7$ & $24.2-30.1$ \\
\hline Weight $<60 \mathrm{~kg}-$ no. (\%) & $139(4.6)$ & $156(5.2)$ & $295(4.9)$ & $469(7.2)$ \\
\hline Previous smoker - no. (\%) & $1027(34.2)$ & $1020(34.0)$ & $2047(34.1)$ & $2314(35.3)$ \\
\hline Current smoker - no. (\%) & $716(23.8)$ & $710(23.7)$ & $1426(23.7)$ & $1361(20.8)$ \\
\hline Diabetes — no. (\%) & $491(16.3)$ & $508(16.9)$ & $999(16.6)$ & $1631(24.9)$ \\
\hline Hypertension — no. (\%) & $1557(51.8)$ & $1548(51.6)$ & $3105(51.7)$ & $4080(62.2)$ \\
\hline Hyperlipidemia - no. (\%) & $953(31.7)$ & $936(31.2)$ & $1889(31.5)$ & $2893(44.1)$ \\
\hline Previous myocardial infarction — no. (\%) & $490(16.3)$ & $484(16.1)$ & $974(16.2)$ & $1831(27.9)$ \\
\hline Previous percutaneous coronary intervention - no. (\%) & $456(15.2)$ & $426(14.2)$ & $882(14.7)$ & $1436(21.9)$ \\
\hline Previous coronary-artery bypass grafting — no. (\%) & $152(5.1)$ & $141(4.7)$ & $293(4.9)$ & $653(10.0)$ \\
\hline Previous stroke - no. (\%) & $115(3.8)$ & $125(4.2)$ & $240(4.0)$ & $467(7.1)$ \\
\hline $\begin{array}{l}\text { Cardiopulmonary resuscitation before arrival at the } \\
\text { catheterization laboratory - no. (\%) }\end{array}$ & $26(0.9)$ & $20(0.7)$ & $46(0.8)$ & $83(1.3)$ \\
\hline Killip class II, III, or IV - no. (\%) & $108(3.6)$ & $86(2.9)$ & $194(3.2)$ & 519 (7.9) \\
\hline
\end{tabular}

* No comparisons between treatment groups were significant. All comparisons between patients who were enrolled in the trial and screened patients who were not enrolled in the trial were significant $(\mathrm{P}<0.005)$, except for body-mass index $(\mathrm{P}=0.74)$. Additional data are provided in Table S1 in the Supplementary Appendix. STEMI denotes ST-segment elevation myocardial infarction.

$\uparrow$ The body-mass index is the weight in kilograms divided by the square of the height in meters.

Killip class II indicates the presence of rales in the lung, class III the presence of acute pulmonary edema, and class IV the presence of cardiogenic shock.

days after PCI (Table 2). At 180 days, a primary end-point event of death from any cause, myocardial infarction, or major bleeding had occurred in $12.3 \%$ of the patients (369 of 3004) in the bivalirudin group and in $12.8 \%$ (383 of 3002) in the heparin group (hazard ratio, 0.96; 95\% confidence interval [CI], 0.83 to $1.10 ; \mathrm{P}=0.54$ ) (Fig. 1 and Table 3). Myocardial infarction had occurred in $2.0 \%$ of the patients in the bivalirudin group and in $2.4 \%$ in the heparin group (hazard ratio, $0.84 ; 95 \% \mathrm{CI}, 0.60$ to 1.19 ; $\mathrm{P}=0.33$ ), major bleeding in $8.6 \%$ and $8.6 \%$, respectively (hazard ratio, 1.00; 95\% CI, 0.84 to 1.19; $\mathrm{P}=0.98$ ), and definite stent thrombosis in
$0.4 \%$ and $0.7 \%$, respectively (hazard ratio, 0.54 ; $95 \%$ CI, 0.27 to $1.10 ; \mathrm{P}=0.09$ ). Death had occurred in $2.9 \%$ of the patients in the bivalirudin group and in $2.8 \%$ in the heparin group (hazard ratio, $1.05 ; 95 \% \mathrm{CI}, 0.78$ to $1.41 ; \mathrm{P}=0.76$ ). The rates of stroke and intraprocedural stent thrombosis (reported by the physician) did not differ significantly between the groups (Table 3 ).

Results were consistent between patients with STEMI and those with NSTEMI and across all other prespecified subgroups, including risk groups defined according to age ( $>65$ years vs. $\leq 65$ years) and according to the presence or absence of chronic renal failure, diabetes mellitus, 


\begin{tabular}{|c|c|c|c|c|}
\hline Outcome & $\begin{array}{l}\text { Bivalirudin } \\
\text { Group } \\
(\mathrm{N}=3004)\end{array}$ & $\begin{array}{l}\text { Heparin } \\
\text { Group } \\
(\mathrm{N}=3002)\end{array}$ & $\begin{array}{l}\text { Hazard Ratio } \\
\text { (95\% CI) }\end{array}$ & P Value \\
\hline & \multicolumn{2}{|c|}{ no. (\%) } & & \\
\hline $\begin{array}{l}\text { Primary end point: death from any cause, myocardial } \\
\text { infarction, or major bleeding }\end{array}$ & $216(7.2)$ & $241(8.0)$ & $0.89(0.74-1.07)$ & 0.21 \\
\hline Death from any cause & $57(1.9)$ & $52(1.7)$ & $1.10(0.75-1.60)$ & 0.63 \\
\hline Death from cardiovascular causes & $54(1.8)$ & $49(1.6)$ & $1.10(0.75-1.62)$ & 0.62 \\
\hline Myocardial infarction & $23(0.8)$ & $33(1.1)$ & $0.70(0.41-1.18)$ & 0.18 \\
\hline Major bleeding & $152(5.1)$ & $169(5.6)$ & $0.89(0.72-1.11)$ & 0.32 \\
\hline BARC type 2 & $100(3.3)$ & $114(3.8)$ & & \\
\hline BARC type 3 & $53(1.8)$ & $53(1.8)$ & & \\
\hline BARC type 5 & $4(0.1)$ & $3(0.1)$ & & \\
\hline Stent thrombosis' & $50(1.7)$ & $53(1.8)$ & $0.94(0.64-1.39)$ & 0.77 \\
\hline Definite & $8(0.3)$ & $20(0.7)$ & $0.40(0.18-0.91)$ & 0.03 \\
\hline Probable & $11(0.4)$ & $11(0.4)$ & & \\
\hline Stroke & $21(0.7)$ & $23(0.8)$ & $1.00(0.52-1.92)$ & 1.00 \\
\hline Primary hemorrhagic stroke & $5(0.2)$ & 0 & & \\
\hline Death, myocardial infarction, major bleeding, or stroke & $226(7.5)$ & $253(8.4)$ & $0.89(0.74-1.06)$ & 0.19 \\
\hline Death, myocardial infarction, or BARC type 3 or 5 bleeding & $124(4.1)$ & $131(4.4)$ & $0.94(0.74-1.21)$ & 0.64 \\
\hline
\end{tabular}

* On the Bleeding Academic Research Consortium (BARC) scale for bleeding, type 2 indicates any overt, actionable sign of bleeding; type 3 bleeding with a decrease in the hemoglobin of $>3 \mathrm{~g}$ per deciliter, any transfusion, cardiac tamponade, or intracranial or ocular involvement; and type 5 fatal bleeding.

$\uparrow$ This includes definite, probable, and intraprocedural stent thrombosis.

and smoking (Fig. 2). The rate of the primary end point was lower among women in the bivalirudin group than among women in the heparin group, although the interaction between sex and treatment group did not reach statistical significance ( $\mathrm{P}=0.05$ for interaction) (Fig. 2). Mortality at 180 days was lower among patients who were enrolled in the trial and underwent randomization (2.9\% [172 of 6006 patients]) than among those who were screened but not enrolled in the trial (8.1\% [528 of 6555]).

\section{DISCUSSION}

In this investigator-initiated, registry-based, randomized clinical trial, we enrolled patients with acute coronary syndromes who were undergoing PCI and receiving treatment with aspirin and potent $\mathrm{P}_{2} \mathrm{Y}_{12}$ inhibitors, without the planned use of glycoprotein IIb/IIIa inhibitors. In these patients, anticoagulation with bivalirudin was not superior to anticoagulation with heparin with respect to the composite end point of death from any cause, myocardial infarction, or major bleeding at 180 days. The rates of the prespecified secondary end points, including the individual components of the primary end point and stent thrombosis, did not differ significantly between the treatment groups. The results were consistent between patients with STEMI and those with NSTEMI and across major patient subgroups, regardless of baseline clinical and angiographic characteristics.

The low rates of ischemic events overall and the absence of a significant between-group difference in event rates may have been influenced by the robust antithrombotic regimen used in the trial. A total of $62 \%$ of the patients received potent $\mathrm{P}_{12} \mathrm{Y}_{12}$ inhibitors at least 1 hour before PCI. A small bolus of heparin was often administered before randomization, because observational analyses have suggested that this strategy may 


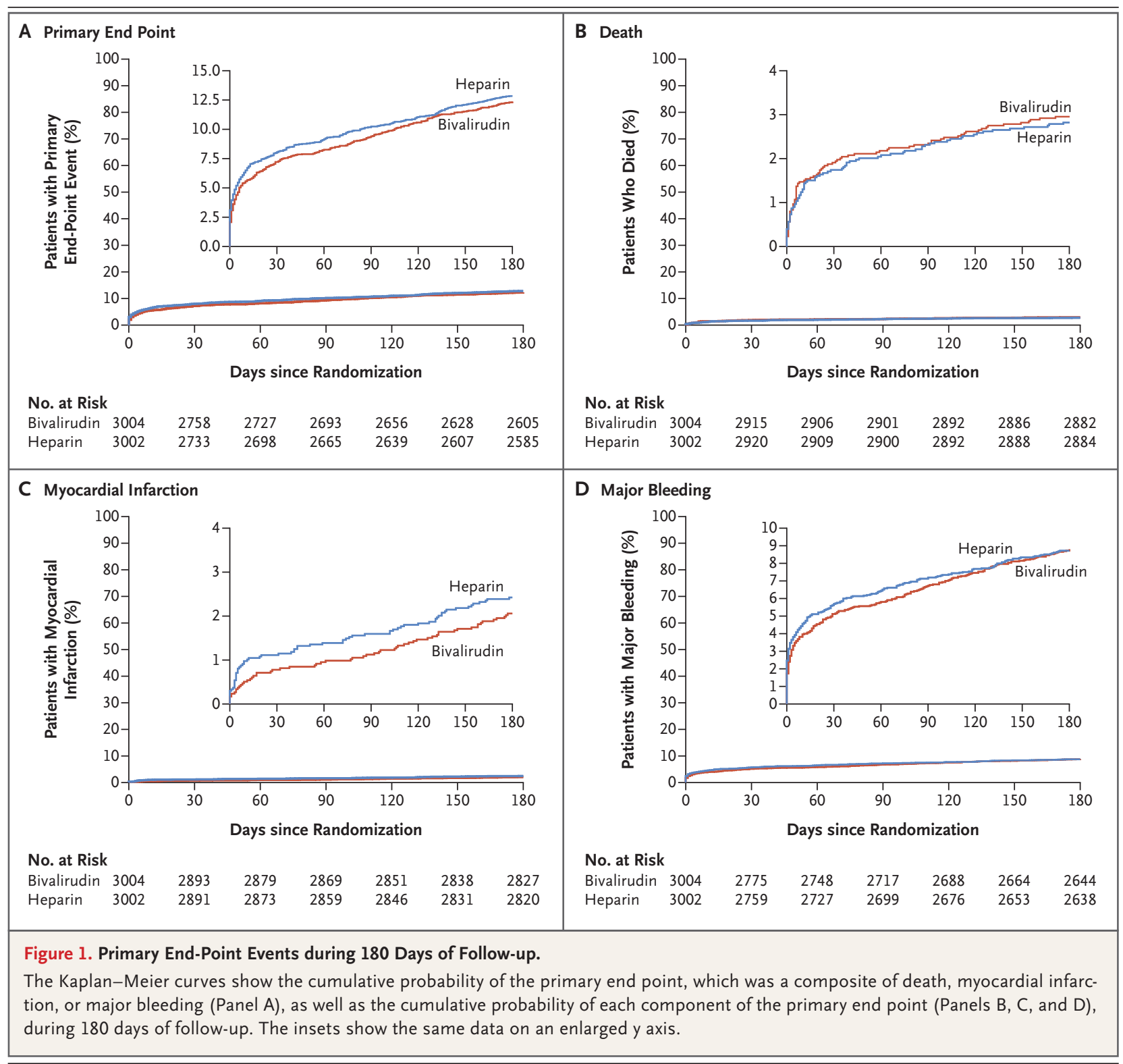

lower the risk of stent thrombosis and death among patients with STEMI who are undergoing primary PCI. ${ }^{16,17}$ A total of $65 \%$ of the patients received a prolonged infusion of high-dose bivalirudin, because previous post hoc analyses have indicated that such a regimen may prevent early stent thrombosis. ${ }^{10,18}$ The low rates of intraprocedural thrombotic events in the trial $(1.0 \%$ in the bivalirudin group and $0.8 \%$ in the heparin group) were consistent with recently reported rates. ${ }^{19}$ The rates of definite stent thrombosis were low at 30 days $(0.3 \%$ in the bivalirudin group and $0.7 \%$ in the heparin group) and at 180 days ( $0.4 \%$ and $0.7 \%$, respectively), whereas in the HEAT-PPCI (How Effective are Antithrombotic Therapies in Primary Percutaneous Coronary Intervention) trial, ${ }^{5}$ a trial in which a prolonged infusion of bivalirudin was not used, the rate of stent thrombosis among patients with STEMI who received bivalirudin was higher $(3.3 \%$ at 28 days).

As expected, the component of the primary composite end point in this trial that occurred most frequently was major bleeding, which ac- 


\begin{tabular}{|c|c|c|c|c|}
\hline Outcome & $\begin{array}{l}\text { Bivalirudin } \\
\text { Group } \\
(\mathrm{N}=3004)\end{array}$ & $\begin{array}{l}\text { Heparin } \\
\text { Group } \\
(\mathrm{N}=3002)\end{array}$ & $\begin{array}{c}\text { Hazard Ratio } \\
(95 \% \mathrm{CI})\end{array}$ & $P$ Value \\
\hline & \multicolumn{2}{|c|}{ no. (\%) } & & \\
\hline $\begin{array}{l}\text { Primary end point: death from any cause, myocardial } \\
\text { infarction, or major bleeding }\end{array}$ & $369(12.3)$ & $383(12.8)$ & $0.96(0.83-1.10)$ & 0.54 \\
\hline Death from any cause & $88(2.9)$ & $84(2.8)$ & $1.05(0.78-1.41)$ & 0.76 \\
\hline Death from cardiovascular causes & $73(2.4)$ & $70(2.3)$ & $1.04(0.75-1.45)$ & 0.80 \\
\hline Myocardial infarction & $60(2.0)$ & $71(2.4)$ & $0.84(0.60-1.19)$ & 0.33 \\
\hline Periprocedural type 4a myocardial infarction & $5(0.2)$ & $2(0.1)$ & & \\
\hline Major bleeding & $259(8.6)$ & $257(8.6)$ & $1.00(0.84-1.19)$ & 0.98 \\
\hline BARC type 2 & $170(5.7)$ & $180(6.0)$ & & \\
\hline BARC type 3 & $94(3.1)$ & $87(2.9)$ & & \\
\hline BARC type 5 & $6(0.2)$ & $3(0.1)$ & & \\
\hline Bleeding at the access site & $68(2.3)$ & $86(2.9)$ & & \\
\hline Stent thrombosis $\dagger$ & $56(1.9)$ & $59(2.0)$ & $0.95(0.66-1.37)$ & 0.78 \\
\hline Definite & $12(0.4)$ & $22(0.7)$ & $0.54(0.27-1.10)$ & 0.09 \\
\hline Probable & $11(0.4)$ & $11(0.4)$ & & \\
\hline Possible & $3(0.1)$ & $4(0.1)$ & & \\
\hline Intraprocedural & $31(1.0)$ & $24(0.8)$ & $1.30(0.76-2.21) *$ & 0.34 \\
\hline Stroke & $25(0.8)$ & $25(0.8)$ & $1.00(0.57-1.74)$ & 1.00 \\
\hline Primary hemorrhagic stroke & $5(0.2)$ & 0 & & \\
\hline Death, myocardial infarction, major bleeding, or stroke & $379(12.6)$ & $398(13.3)$ & $0.94(0.82-1.09)$ & 0.42 \\
\hline Death, myocardial infarction, or BARC type 3 or 5 bleeding & $221(7.4)$ & $226(7.5)$ & $0.97(0.81-1.17)$ & 0.78 \\
\hline
\end{tabular}

counted for two thirds of the primary end-point events. Two thirds of all major bleeding events were moderate (BARC type 2) and one third were severe (BARC type 3 or 5 ). Only severe bleeding events are associated with a mortality similar to that of myocardial infarction. ${ }^{20}$ The low and similar mortality in the two treatment groups was therefore probably due to the low rates of both myocardial infarction and severe bleeding. These findings contrast with findings from the BRIGHT (Bivalirudin in Acute Myocardial Infarction vs. Heparin and GPI Plus Heparin Trial) study, ${ }^{12}$ which showed a lower rate of adverse clinical events (the composite of ischemic events or bleeding) with bivalirudin than with heparin; the lower rate with bivalirudin was associated primarily with a lower rate of bleeding. Two large contemporary trials that compared bivalirudin with heparin and allowed the planned use of glycoprotein IIb/IIIa inhibitors in the heparin group showed lower rates of bleeding events but higher rates of stent thrombosis in the bivalirudin group than in the heparin group. ${ }^{10,11}$ A subgroup analysis also showed lower rates of bleeding but higher rates of stent thrombosis in the bivalirudin group among patients for whom the planned use of glycoprotein IIb/IIIa inhibitors was not allowed. ${ }^{21}$ In our trial, the use of the recommended radialartery access for PCI in more than $90 \%$ of the patients and the low use of glycoprotein IIb/IIIa inhibitors may have contributed to the very low rate of bleeding events in both treatment groups.

Several limitations of the trial should be noted. First, patients who were not enrolled in the trial were at higher risk for a primary endpoint event than those who were enrolled, and 


\begin{tabular}{|c|c|c|c|c|c|c|}
\hline \multirow{3}{*}{$\begin{array}{l}\text { Subgroup } \\
\text { Overall }\end{array}$} & \multirow{2}{*}{\multicolumn{2}{|c|}{$\begin{array}{l}\text { Bivalirudin } \quad \text { Heparin } \\
\text { no. of events/total no. of patients (\%) }\end{array}$}} & \multicolumn{3}{|c|}{ Hazard Ratio $(95 \% \mathrm{Cl})$} & \multirow{3}{*}{$\begin{array}{c}\text { P Value } \\
0.54\end{array}$} \\
\hline & & & & & & \\
\hline & $369 / 3004(12.3)$ & $383 / 3002$ (12.8) & $\rightarrow$ & - & $0.96(0.83-1.10)$ & \\
\hline Type of myocardial infarction & & & & & & 0.97 \\
\hline NSTEMI & $182 / 1503(12.1)$ & $187 / 1498$ (12.5) & $\longrightarrow$ & 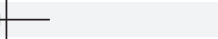 & $0.96(0.78-1.18)$ & \\
\hline STEMI & $187 / 1501(12.5)$ & 196/1504 (13.0) & $\longrightarrow$ & + & $0.95(0.78-1.17)$ & \\
\hline Sex & & & & & & 0.05 \\
\hline Female & 105/771 (13.6) & $140 / 821(17.1)$ & $\longrightarrow$ & & $0.78(0.60-1.00)$ & \\
\hline Male & $263 / 2229$ (11.8) & $243 / 2177$ (11.2) & - & $=$ & $1.06(0.89-1.26)$ & \\
\hline Age & & & & & & 0.70 \\
\hline$>65 \mathrm{yr}$ & 289/1819 (15.9) & 299/1852 (16.1) & $\longrightarrow$ & - & $0.97(0.83-1.15)$ & \\
\hline$\leq 65 \mathrm{yr}$ & 79/1181 (6.7) & $84 / 1146(7.3)$ & $\longrightarrow$ & - & $0.91(0.67-1.24)$ & \\
\hline Diabetes mellitus & & & & & & 0.82 \\
\hline Yes & 74/491 (15.1) & $82 / 508(16.1)$ & $\longrightarrow$ & - & $0.93(0.68-1.27)$ & \\
\hline No & 293/2502 (11.7) & 299/2482 (12.0) & $\longrightarrow$ & - & $0.97(0.82-1.13)$ & \\
\hline Renal failure & & & & & & 0.16 \\
\hline Yes & $101 / 450(22.4)$ & 95/477 (19.9) & $\longrightarrow$ & $\rightarrow$ & $1.13(0.85-1.50)$ & \\
\hline No & 258/2511 (10.3) & 283/2484 (11.4) & $\longrightarrow$ & + & $0.89(0.75-1.06)$ & \\
\hline Smoker & & & & & & 0.97 \\
\hline Yes & $81 / 716(11.3)$ & $85 / 710(12.0)$ & $\rightarrow$ & 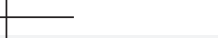 & $0.95(0.70-1.29)$ & \\
\hline No & $277 / 2209(12.5)$ & $290 / 2205$ (13.2) & $\rightarrow$ & - & $0.94(0.80-1.11)$ & \\
\hline Weight & & & & & & 0.38 \\
\hline$<60 \mathrm{~kg}$ & $28 / 139(20.1)$ & $27 / 156(17.3)$ & & $\rightarrow$ & $1.19(0.70-2.02)$ & \\
\hline$\geq 60 \mathrm{~kg}$ & $335 / 2847$ (11.8) & $355 / 2829$ (12.5) & $\rightarrow-$ & - & $0.93(0.80-1.08)$ & \\
\hline Previous myocardial infarction & & & & & & 0.55 \\
\hline Yes & $61 / 490(12.4)$ & $69 / 484(14.3)$ & $=$ & - & $0.86(0.61-1.22)$ & \\
\hline No & $300 / 2474(12.1)$ & $307 / 2467$ (12.4) & $\longrightarrow$ & - & $0.97(0.83-1.13)$ & \\
\hline Previous $\mathrm{PCl}$ & & & & & & 0.39 \\
\hline Yes & $60 / 456(13.2)$ & $66 / 426(15.5)$ & - & - & $0.83(0.58-1.17)$ & \\
\hline No & $308 / 2544(12.1)$ & $317 / 2572(12.3)$ & - & - & $0.98(0.84-1.14)$ & \\
\hline Target vessel & & & & & & 0.50 \\
\hline Left coronary artery & $221 / 1807$ (12.2) & $248 / 1848(13.4)$ & $\because$ & - & $0.90(0.75-1.08)$ & \\
\hline Right coronary artery & $97 / 807(12.0)$ & 96/806 (11.9) & 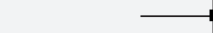 & 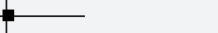 & $1.01(0.76-1.34)$ & \\
\hline Thrombus grade & & & & & & 0.91 \\
\hline $0-3$ & $313 / 2589(12.1)$ & $328 / 2587(12.7)$ & $\rightarrow-$ & - & $0.94(0.81-1.10)$ & \\
\hline 4 or 5 & $52 / 398(13.1)$ & $55 / 405(13.6)$ & 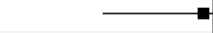 & | & $0.97(0.66-1.41)$ & \\
\hline Access site for $\mathrm{PCl}$ & & & & & & 0.89 \\
\hline Femoral & $65 / 290(22.4)$ & $64 / 280(22.9)$ & $\longrightarrow$ & - & $0.97(0.69-1.37)$ & \\
\hline Radial & $303 / 2708$ (11.2) & $319 / 2716$ (11.7) & $=$ & - & $0.95(0.81-1.11)$ & \\
\hline $\begin{array}{l}\text { Time from administration } \\
\text { of } \mathrm{P}_{2} \mathrm{Y}_{12} \text { inhibitor to } \mathrm{PCl}\end{array}$ & & & & & & 0.62 \\
\hline$<1 \mathrm{hr}$ & $144 / 1148$ (12.5) & $161 / 1129(14.3)$ & $\longrightarrow$ & - & $0.87(0.69-1.09)$ & \\
\hline $1-2 \mathrm{hr}$ & $73 / 588(12.4)$ & $75 / 604(12.4)$ & - & 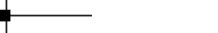 & $1.00(0.72-1.37)$ & \\
\hline$>2 \mathrm{hr}$ & $146 / 1252$ (11.7) & $144 / 1256$ (11.5) & 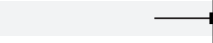 & 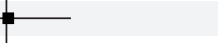 & $1.01(0.80-1.27)$ & \\
\hline TIMI flow grade before $\mathrm{PCI}$ & & & & & & 0.53 \\
\hline 0 & $151 / 1178$ (12.8) & 133/1114 (11.9) & $\longrightarrow$ & - & $1.08(0.86-1.37)$ & \\
\hline 1 & $28 / 222(12.6)$ & $33 / 220(15.0)$ & - & 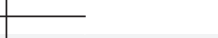 & $0.81(0.49-1.34)$ & \\
\hline 2 & $58 / 483(12.0)$ & $61 / 487(12.5)$ & $\longrightarrow$ & - & $0.94(0.66-1.35)$ & \\
\hline 3 & $130 / 1113$ (11.7) & $156 / 1178(13.2)$ & $\longrightarrow$ & - & $0.87(0.69-1.09)$ & \\
\hline Thrombus aspiration & & & & & & 0.73 \\
\hline Yes & $15 / 169(8.9)$ & $16 / 153(10.5)$ & $\rightarrow-$ & & $0.85(0.42-1.71)$ & \\
\hline No & $353 / 2831(12.5)$ & $367 / 2845$ (12.9) & $\longrightarrow$ & - & $0.96(0.83-1.11)$ & \\
\hline Maximum ACT <median ACT & & & & & & 0.84 \\
\hline Yes & $111 / 926$ (12.0) & $158 / 1238(12.8)$ & $\longrightarrow$ & - & $0.93(0.73-1.18)$ & \\
\hline No & 139/1183 (11.7) & $160 / 1239(12.9)$ & $\longrightarrow$ & 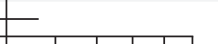 & $0.90(0.72-1.13)$ & \\
\hline & & & $0.8 \quad 1$. & $1.6 \quad 2.0$ & & \\
\hline & & & Bivalirudin Better & Heparin Better & & \\
\hline
\end{tabular}


Figure 2 (facing page). Subgroup Analysis of the Primary End Point.

Thrombus grades range from 0 to 5 , with higher grades indicating a larger thrombus. ACT denotes activated clotting time, NSTEMI non-ST-segment elevation myocardial infarction, $\mathrm{PCl}$ percutaneous coronary intervention, STEMI ST-segment elevation myocardial infarction, and TIMI Thrombolysis in Myocardial Infarction.

thus the trial population may not be representative of all patients undergoing PCI for acute myocardial infarction. Second, the trial had an open-label design, which could have biased the physicians who provided care in identifying possible outcome events. Third, follow-up data were obtained by means of telephone call or review of hospital records, and office evaluations were not planned, which may have resulted in missed outcome events or biases due to patient recall. Finally, most patients were treated with a small dose of heparin before randomization, which may have limited the likelihood of detecting a difference in effect between the trial drugs.
In summary, VALIDATE-SWEDEHEART was a registry-based, randomized, controlled trial that compared bivalirudin with heparin monotherapy among patients with STEMI or NSTEMI who were undergoing PCI predominantly with the use of a radial approach and were receiving treatment with high-intensity platelet inhibitors. We found no significant difference between treatment with bivalirudin and treatment with heparin with respect to the rate of death, repeat myocardial infarction, or major bleeding events during 180 days of follow-up.

Supported by the Swedish Heart-Lung Foundation, the Swedish Research Council, unrestricted grants from AstraZeneca and the Medicines Company, and the Swedish Foundation for Strategic Research (as part of the TOTAL-AMI project).

Disclosure forms provided by the authors are available with the full text of this article at NEJM.org.

We thank the patients and staff at all the centers who participated in the VALIDATE-SWEDEHEART collaboration for their commitment to this trial; Ylva Lindman, Anna Stendahl, Frida Kåver, and Solveig Wennerholm for trial management; Gorm Boje Jensen, Lars Köber, and Gunnar Gislason for participation in the data and safety monitoring committee; and Vendela Roos, Ph.D. (Uppsala Clinical Research Center, Uppsala University, Uppsala, Sweden), for editorial assistance.

\section{APPENDIX}

The authors' full names and academic degrees are as follows: David Erlinge, M.D., Ph.D., Elmir Omerovic, M.D., Ph.D., Ole Fröbert, M.D., Ph.D., Rikard Linder, M.D., Ph.D., Mikael Danielewicz, M.D., Mehmet Hamid, M.D., Eva Swahn, M.D., Ph.D., Loghman Henareh, M.D., Ph.D., Henrik Wagner, M.D., Ph.D., Peter Hårdhammar, M.D., Iwar Sjögren, M.D., Jason Stewart, M.D., Per Grimfjärd, M.D., Jens Jensen, M.D., Ph.D., Mikael Aasa, M.D., Ph.D., Lotta Robertsson, M.D., Pontus Lindroos, M.D., Jan Haupt, M.D., Helena Wikström, M.D., Anders Ulvenstam, M.D., Pallonji Bhiladvala, M.D., Bo Lindvall, M.D., Anders Lundin, M.D., Tim Tödt, M.D., Ph.D., Dan Ioanes, M.D., Truls Råmunddal, M.D., Ph.D., Thomas Kellerth, M.D., Leszek Zagozdzon, M.D., Matthias Götberg, M.D., Ph.D., Jonas Andersson, M.D., Ph.D., Oskar Angerås, M.D., Ph.D., Ollie Östlund, Ph.D., Bo Lagerqvist, M.D., Ph.D., Claes Held, M.D., Ph.D., Lars Wallentin, M.D., Ph.D., Fredrik Scherstén, M.D., Ph.D., Peter Eriksson, M.D., Ph.D., Sasha Koul, M.D., Ph.D., and Stefan James, M.D., Ph.D.

The authors' affiliations are as follows: the Department of Cardiology, Clinical Sciences, Lund University, Lund (D.E., P.B., A.L., T.T., M.G., F.S., S.K.), the Department of Cardiology, Sahlgrenska University Hospital, Gothenburg (E.O., D.I., T.R., O.A.), the Department of Cardiology, Faculty of Health, Örebro University, Örebro (O.F., T.K., L.Z.), the Department of Cardiology, Danderyd Hospital (R.L.), and the Department of Cardiology, Karolinska University Hospital (L.H.), Karolinska Institutet, the Department of Cardiology, Capio St. Görans Hospital (J.J., P.L.), and the Department of Cardiology, Södersjukhuset AB (M.A.), Stockholm, PCI-Unit at Karlstad Hospital, Karlstad (M.D.), the Department of Cardiology, Mälarsjukhuset, Eskilstuna (M.H.), the Department of Cardiology, Linköping University Hospital, Linköping (E.S.), the Department of Cardiology, Helsingborg Lasarett, Helsingborg (H. Wagner), the Department of Cardiology, Halmstad Hospital, Halmstad (P.H.), the Department of Cardiology, Falun Hospital, Falun (I.S.), the Department of Cardiology, Skaraborgs Hospital, Skövde (J.S.), the Department of Internal Medicine, Västmanlands Sjukhus, Västerås (P.G.), the Department of Cardiology, Södra Älvsborgs Sjukhus, Borås (L.R.), the Department of Cardiology, Sunderby Sjukhus, Luleå (J.H.), the Department of Cardiology, Kristianstad Hospital, Kristianstad (H. Wikström), the Department of Cardiology, Östersund Hospital, Östersund (A.U.), the Department of Cardiology, Sundsvall Hospital, Sundsvall (B. Lindvall), the Department of Cardiology, Umeå University, Umeå J.A., P.E.), and the Department of Medical Sciences and Uppsala Clinical Research Center, Uppsala University, Uppsala (O.Ö., B. Lagerqvist, C.H., L.W., S.J.) - all in Sweden.

\section{REFERENCES}

1. Stone GW, Witzenbichler B, Guagliumi $\mathrm{G}$, et al. Bivalirudin during primary $\mathrm{PCI}$ in acute myocardial infarction. $\mathrm{N}$ Engl J Med 2008;358:2218-30.

2. Lincoff AM, Bittl JA, Harrington RA, et al. Bivalirudin and provisional glycoprotein IIb/IIIa blockade compared with heparin and planned glycoprotein IIb/IIIa blockade during percutaneous coronary intervention: REPLACE-2 randomized trial. JAMA 2003;289:853-63.

3. Montalescot G, Barragan P, Wittenberg $\mathrm{O}$, et al. Platelet glycoprotein IIb/IIIa inhibition with coronary stenting for acute myocardial infarction. N Engl J Med 2001; 344:1895-903.
4. Montalescot G, Zeymer U, Silvain J, et al. Intravenous enoxaparin or unfractionated heparin in primary percutaneous coronary intervention for ST-elevation myocardial infarction: the international randomised open-label ATOLL trial. Lancet 2011;378:693-703.

5. Shahzad A, Kemp I, Mars C, et al. Un- 
fractionated heparin versus bivalirudin in primary percutaneous coronary intervention (HEAT-PPCI): an open-label, single centre, randomised controlled trial. Lancet 2014;384:1849-58.

6. Stone GW, McLaurin BT, Cox DA, et al. Bivalirudin for patients with acute coronary syndromes. N Engl J Med 2006; 355:2203-16.

7. Wiviott SD, Braunwald E, McCabe CH, et al. Prasugrel versus clopidogrel in patients with acute coronary syndromes. N Engl J Med 2007;357:2001-15.

8. Wallentin L, Becker RC, Budaj A, et al. Ticagrelor versus clopidogrel in patients with acute coronary syndromes. $\mathrm{N}$ Engl J Med 2009;361:1045-57.

9. Kastrati A, Neumann FJ, Schulz S, et al. Abciximab and heparin versus bivalirudin for non-ST-elevation myocardial infarction. N Engl J Med 2011;365:1980-9.

10. Valgimigli M, Frigoli E, Leonardi S, et al. Bivalirudin or unfractionated heparin in acute coronary syndromes. N Engl J Med 2015;373:997-1009.

11. Steg PG, van 't Hof A, Hamm CW, et al. Bivalirudin started during emergency transport for primary PCI. N Engl J Med 2013; 369:2207-17.

12. Han Y, Guo J, Zheng Y, et al. Bivalirudin vs heparin with or without tirofiban during primary percutaneous coronary intervention in acute myocardial infarc- tion: the BRIGHT randomized clinical trial. JAMA 2015;313:1336-46.

13. Schulz S, Richardt G, Laugwitz KL, et al. Prasugrel plus bivalirudin vs. clopidogrel plus heparin in patients with STsegment elevation myocardial infarction. Eur Heart J 2014;35:2285-94.

14. Erlinge D, Koul S, Eriksson P, et al. Bivalirudin versus heparin in non-ST and ST-segment elevation myocardial infarction-a registry-based randomized clinical trial in the SWEDEHEART registry (the VALIDATE-SWEDEHEART trial). Am Heart J 2016;175:36-46.

15. Windecker S, Kolh P, Alfonso F, et al 2014 ESC/EACTS guidelines on myocardial revascularization: the task force on myocardial revascularization of the European Society of Cardiology (ESC) and the European Association for Cardio-Thoracic Surgery (EACTS): developed with the special contribution of the European Association of Percutaneous Cardiovascular Interventions (EAPCI). Eur Heart J 2014;35:2541-619. 16. Dangas GD, Caixeta A, Mehran R, et al. Frequency and predictors of stent thrombosis after percutaneous coronary intervention in acute myocardial infarction. Circulation 2011;123:1745-56.

17. Koutouzis M, Lagerqvist B, James S, et al. Unfractionated heparin administration in patients treated with bivalirudin during primary percutaneous coronary intervention is associated lower mortality and target lesion thrombosis: a report from the Swedish Coronary Angiography and Angioplasty Registry (SCAAR). Heart 2011;97:1484-8.

18. Clemmensen P, Wiberg S, Van't Hof A, et al. Acute stent thrombosis after primary percutaneous coronary intervention: insights from the EUROMAX trial (European Ambulance Acute Coronary Syndrome Angiography). JACC Cardiovasc Interv 2015;8:214-20.

19. Bhatt DL, Stone GW, Mahaffey KW, et al. Effect of platelet inhibition with cangrelor during PCI on ischemic events. N Engl J Med 2013;368:1303-13.

20. Eikelboom JW, Mehta SR, Anand SS, Xie C, Fox KA, Yusuf S. Adverse impact of bleeding on prognosis in patients with acute coronary syndromes. Circulation 2006;114:774-82.

21. Zeymer U, van 't Hof A, Adgey J, et al. Bivalirudin is superior to heparins alone with bailout GP IIb/IIIa inhibitors in patients with ST-segment elevation myocardial infarction transported emergently for primary percutaneous coronary intervention: a pre-specified analysis from the EUROMAX trial. Eur Heart J 2014;35: 2460-7.

Coppright @ 2017 Massachusetts Medical Society.

RECEIVE IMMEDIATE NOTIFICATION WHEN AN ARTICLE IS PUBLISHED ONLINE FIRST

To be notified by e-mail when Journal articles are published Online First, sign up at NEJM.org. 